\title{
Microstructure, Wear Resistance and Oxidation Behavior of Ni-Ti-Si Coatings Fabricated on Ti6A14V by Laser Cladding
}

\author{
Qiaoqiao Zhuang ${ }^{1,2}$, Peilei Zhang ${ }^{1,2, *}$, Mingchuan $\mathrm{Li}^{1,2}$, Hua Yan ${ }^{1,2}$, Zhishui $\mathrm{Yu}^{1,2}$ and \\ Qinghua $\mathrm{Lu}^{1,2}$ \\ 1 School of Materials Engineering, Shanghai University of Engineering Science, Shanghai 201620, China; \\ zh80836971@163.com (Q.Z.); 15317538065@163.com (M.L.); yanhua@foxmail.com (H.Y.); \\ yu_zhishui@163.com (Z.Y.); luqh@sues.edu.cn (Q.L.) \\ 2 Shanghai Collaborative Innovation Center of Laser Advanced Manufacturing Technology, \\ Shanghai 201620, China \\ * Correspondence: peilei@sues.edu.cn; Tel.: +86-21-6779-1412
}

Received: 8 September 2017; Accepted: 20 October 2017; Published: 30 October 2017

\begin{abstract}
The Ni-Ti-Si composite coatings were successfully fabricated on Ti6Al4V by laser cladding. The microstructure were studied by SEM (scanning electron microscopy) and EDS (energy dispersive spectrometer). It has been found that $\mathrm{Ti}_{2} \mathrm{Ni}$ and $\mathrm{Ti}_{5} \mathrm{Si}_{3}$ phases exist in all coatings, and some samples have $\mathrm{TiSi}_{2}$ phases. Moreover, due to the existence of these phases, coatings presented relatively higher microhardness than that of the substrate ( $826 \mathrm{HV}$ (Vickers hardness)) and the microhardness value of coating 3 is about twice larger than that of the substrate. During the dry sliding friction and wear test, due to the distribution of the relatively ductile phase of $\mathrm{Ti}_{2} \mathrm{Ni}$ and reinforcement phases of $\mathrm{Ti}_{5} \mathrm{Si}_{3}$ and $\mathrm{TiSi}_{2}$, the coatings performed good wear resistance. The oxidation process contains two stages: the rapid oxidation and slow oxidation by high temperature oxidation test at $800{ }^{\circ} \mathrm{C}$ for $50 \mathrm{~h}$. Meanwhile, the value of the oxidation weight gain of the substrate is approximately three times larger than that of the coating 4 . During the oxidation process, the oxidation film formed on the coating is mainly consisted of $\mathrm{TiO}_{2}, \mathrm{Al}_{2} \mathrm{O}_{3}$ and $\mathrm{SiO}_{2}$. Phases $\mathrm{Ti}_{2} \mathrm{Ni}, \mathrm{Ti}_{5} \mathrm{Si}_{3}, \mathrm{TiSi}_{2}$ and $\mathrm{TiSi}$ were still found and it could be responsible for the improvement in oxidation resistance of the coatings by laser cladding.
\end{abstract}

Keywords: Ni-Ti-Si composite coatings; laser cladding; wear resistance; high-temperature oxidation resistance

\section{Introduction}

Titanium and its alloys are extensively applied in aviation manufacture, medical fields, marine industries and other industries due to their low density, high strength, excellent corrosion resistance and easy formation [1-3]. However, low hardness, poor wear and oxidation resistance severely restrict their further application fields $[4,5]$. To circumvent these problems, many technologies have been applied to improve the wear and corrosion resistance of titanium alloys to prolong their service time. Among them, the laser cladding has received more and more attention [6-9]. Huang et al. [10] fabricated TiVCrAlSi high entropy alloy coatings with little cracks and pores by laser cladding consisted of (Ti, V) ${ }_{5} \mathrm{Si}_{3}$ and a $\mathrm{BCC}$ (body-centered cubic) solid solution. Because of the combination of $(\mathrm{Ti}, \mathrm{V})_{5} \mathrm{Si}_{3}$ phase and ductile BCC solid matrix, the wear resistance in abrasive and adhesive wear coatings was improved significantly compared with the substrate. Weng et al. [11] fabricated metal matrix composites on Ti6Al4V titanium alloy by laser cladding. Because of the reinforced phases of $\mathrm{CoTi}, \mathrm{CoTi}_{2}, \mathrm{NiTi}, \mathrm{TiC}, \mathrm{TiB}_{2}, \mathrm{TiB}, \mathrm{Cr}_{7} \mathrm{C}_{3}$ and $\mathrm{Ti}_{5} \mathrm{Si}_{3}$, the coatings possessed high hardness and exhibited excellent wear resistance. The values of hardness of coatings were enhanced 
by 3-4 times compared with the substrate and the wear mass loss of coatings was approximately 0.083 of substrate. Dong et al. [12] obtained TiC reinforced Ti-Ni-Si intermetallic composite coating by laser cladding on TA15 titanium alloy. It can be seen that the wear resistance was particularly improved and the coating showed insensitive to the test load due to the uniform distribution of $\mathrm{TiC}$ in coating.

Many scholars have also been devoted to investigating the laser cladding coatings to enhance the oxidation resistance of titanium alloys at elevated temperature. Liu et al. [13] prepared the $\mathrm{TiN} / \mathrm{Ti}_{3} \mathrm{Al}$ intermetallic composite coatings on Ti6Al4V substrate by laser cladding. The results of the isothermal oxidation test carried out at $600{ }^{\circ} \mathrm{C}$ showed that the value of relative oxidation resistance of laser cladding coatings was approximately six times bigger than that of the titanium alloy. This change may be attributed to the formation of TiN and $\mathrm{Ti}_{3} \mathrm{Al}$ disputing the diffusion of $\mathrm{O}$ atom. During the oxidation process, the affinity of $\mathrm{Al}$ and $\mathrm{O}$ is stronger than that of $\mathrm{Ti}$ and $\mathrm{O}$ [14] and the $\mathrm{Al}_{2} \mathrm{O}_{3}$ oxide would be preferentially formed on the composite coatings. Therefore, cladding coatings performed excellent oxidation resistance at high temperature. Liu et al. [14] investigated high temperature oxidation resistance of $\mathrm{Ti}_{5} \mathrm{Si}_{3} / \gamma / \mathrm{TiSi}$ composite coatings on $\gamma$-TiAl intermetallic alloy using $\mathrm{NiCr}$-Si powders as precursor material. The conclusion drawn was that the coating consisting of $\mathrm{NiCr}-40 \% \mathrm{Si}$ powders showed better high temperature oxidation resistance at $1000^{\circ} \mathrm{C}$ for $50 \mathrm{~h}$. Due to the brittle and loose $\mathrm{TiO}_{2}$, the oxidation products mainly consisted of $\mathrm{SiO}_{2}$ and $\mathrm{Al}_{2} \mathrm{O}_{3}$, which impeded the diffusion of $\mathrm{O}$ and improved the oxidation resistance of the cladding coating. Lv et al. [15] reported a study on the oxidation behaviors of $\mathrm{TiNi} / \mathrm{Ti}_{2} \mathrm{Ni}$ composite coatings with $\mathrm{TaC}$ addition prepared on $\mathrm{Ti} 6 \mathrm{Al} 4 \mathrm{~V}$ by laser cladding. After the oxidation test, the oxides could be found on the surface of coatings without $\mathrm{TaC}$ were $\mathrm{TiO}_{2}, \mathrm{NiO}, \mathrm{Cr}_{2} \mathrm{O}_{3}, \mathrm{Al}_{2} \mathrm{O}_{3}$ and $\mathrm{SiO}_{2}$. While $\mathrm{TaC}$ was added, $\mathrm{Ta}_{2} \mathrm{O}_{5}$ and $\mathrm{TaC}$ were also found. Moreover, with the increase of $\mathrm{TaC}$, the oxidation rates of coatings were decreasing. The oxidation resistance of coatings was remarkably improved at high temperatures.

There is very limited research on the wear resistance and high temperature oxidation resistance of Ni-Ti-Si laser cladding coatings on the titanium alloy. In this paper, the Ni-Ti-Si coating was synthesized on the Ti6Al4V titanium alloy by laser cladding with different ratios of $\mathrm{Ti}$ and $\mathrm{Si}$ powders. The chemical composition, microstructure, microhardness was investigated in sequence. Wear resistance mechanisms and oxidation behaviors at high temperature were also involved.

\section{Materials and Methods}

In this study, the substrate was Ti6Al4V titanium alloy with the dimensions of $50 \mathrm{~mm} \times 50 \mathrm{~mm} \times 5 \mathrm{~mm}$. The chemical composite of the substrates is listed in Table 1 .

Table 1. Chemical composite of Ti6Al4V titanium alloy (wt \%).

\begin{tabular}{ccccccccc}
\hline Al & $\mathbf{V}$ & $\mathbf{F e}$ & $\mathbf{S i}$ & $\mathbf{C}$ & $\mathbf{N}$ & $\mathbf{H}$ & $\mathbf{O}$ & $\mathbf{T i}$ \\
\hline $5.5-6.8$ & $3.5-4.5$ & $\leq 0.30$ & $\leq 0.15$ & $\leq 0.10$ & $\leq 0.05$ & $\leq 0.015$ & $\leq 0.20$ & Bal. \\
\hline
\end{tabular}

Before laser cladding, the cladding surface was abraded and then cleaned ultrasonically with alcohol. Powders ( $\geq 99.5 \%$ purity) used as precursor materials have an average particle size ranging from $50-75 \mu \mathrm{m}$. Next, the powders were mixed in a ball mill for $3 \mathrm{~h}$. The composition of cladding powders is given in Table 2. The mixed powders were pre-placed onto the substrate surface with the thickness of $1.0 \mathrm{~mm}$. The powders were mixed with a binder $(5 \%$ cellulose acetate + diacetone alcohol solution). The preplaced coating was dried for half an hour at $150{ }^{\circ} \mathrm{C}$. Laser cladding was conducted in the argon shielded chamber of a $5 \mathrm{~kW}$ fiber laser material processing system (IPG YLS-5000, IPG Photonics, Boston, MA, USA) and the spot diameter is $5.0 \mathrm{~mm}$. Figure 1 was the schematic diagram of the shielded chamber. The parameters of laser cladding are shown in Table 2. After laser cladding, the samples of the same coating were divided into four groups: Group 1 was for the XRD (X-ray Diffraction) test; Group 2 was for the microstructural analysis and microhardness test; Group 3 was for the wear test with an overlap ratio of 30\%; and Group 4 was for the oxidation test. 
Table 2. The chemical composite of cladding powders (at \%) and processing parameter.

\begin{tabular}{cccccc}
\hline Coating & Ni & Ti & Si & Laser Power/KW & Scanning Speed/(mm/min) \\
\hline 1 & 35 & 50 & 15 & & \\
2 & 35 & 40 & 25 & 1.5 & 1000 \\
3 & 35 & 30 & 35 & & \\
4 & 35 & 20 & 45 & & \\
\hline
\end{tabular}

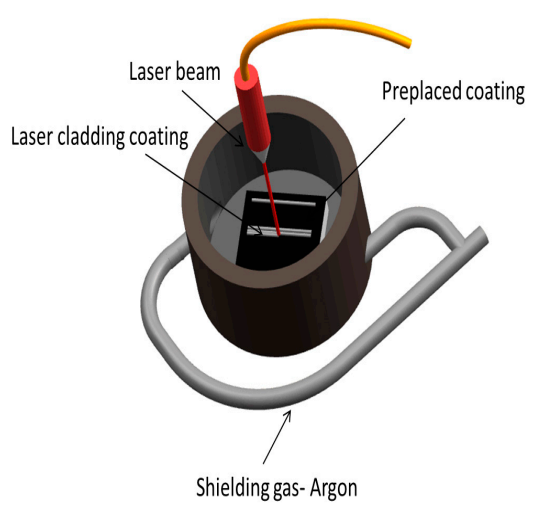

Figure 1. The schematic diagram of the shielded chamber.

The samples of Group 1 were cut and polished with abrasive paper of \#150. Then, the constitution of the coating was identified by a PANalytical X'Pert Pro X-ray diffraction (XRD) (X'Pert Pro, PANalytical, Almelo, The Netherlands) with $\mathrm{Cu} \mathrm{K} \alpha$ radiation $(\lambda=0.154060 \mathrm{~nm})$. The samples of Group 2 were successively ground with abrasive paper of \#150, \#400,\#800,\#1200 and then polished with diamond paste. After this, the specimens were etched in a mixture solution (with the volume of $\mathrm{HF}: \mathrm{HNO}_{3}: \mathrm{H}_{2} \mathrm{O}=7: 43: 50$ ) for 3-5 s. Microstructures and chemical compositions of the coatings were analyzed by a Hitachi S-3400N scanning electron microscope (SEM) (S-3400N, Hitachi, Tokyo, Japan) and a GENESIS EDAX energy dispersive spectrometer (EDS) (GENESIS, EDAX, San Diego, CA, USA) Finally, the microhardness along the depth direction of the specimen was detected by HXD-1000 Vickers (HXD-1000, Taiming Optical Instrument Co. Ltd., Shanghai, China ) with a load of $200 \mathrm{~N}$ and load-dwell time of $15 \mathrm{~s}$.

The dry sliding friction test for Group 3 was conducted on a CETR-UMT Multi-Specimen Test System (UMT-3, Bruker, Karlsruhe, Baden-Württemberg, Germany) at room temperature with an applied load of $150 \mathrm{~N}$ for $60 \mathrm{~min}$. The schematic diagram of the wear test was presented in Figure 2 . The adoptive rotation speed was $100 \mathrm{r} / \mathrm{min}$ and the friction radius was $3 \mathrm{~mm}$. The topographies of wear surface were observed also by SEM.

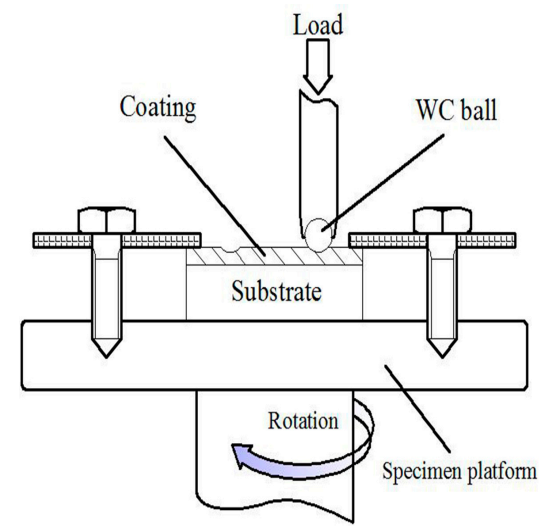

Figure 2. The schematic diagram of the wear test. 
The samples of Group 4 were cut into plates with a size of $5 \mathrm{~mm} \times 3 \mathrm{~mm} \times 0.8 \mathrm{~mm}$ for the oxidation test. The surfaces of the specimen were ground by abrasive papers of \#150, \#400, \#800, \#1200 to make sure the surface smooth. The isothermal oxidation test was conducted in a muffle furnace at $800{ }^{\circ} \mathrm{C}$ for $50 \mathrm{~h}$. The specimens were brought out once an hour to weigh the mass by an analytical balance with the accuracy of $0.1 \mathrm{mg}$.

\section{Results and Discussion}

\subsection{XRD Results and Microstructures}

The XRD patterns of the laser cladding coatings with different contents are shown in Figure 3. According to the Figure 3, it can be seen that the coatings are mainly composed of $\mathrm{Ti}_{2} \mathrm{Ni}, \mathrm{TiSi}_{2}$ and $\mathrm{Ti}_{5} \mathrm{Si}_{3}$ phases. In general, laser cladding is a rapid melting and nonequilibrium solidification process; hence, multi-phases coexist and some diffraction peaks overlap, even diverging from the equilibrium positions in cladding coatings. With the content of Ti decreasing, the phases of the coatings change correspondingly. The diffraction peaks of coating1 are in accordance with JCPDS cards (No. 01-072-0442 and No. 00-018-0898 for $\mathrm{Ti}_{2} \mathrm{Ni}$, No. 03-065-3597 for $\left.\mathrm{Ti}_{5} \mathrm{Si}_{3}\right)$. It can demonstrate that the coating 1 is primarily constituted of $\mathrm{Ti}_{2} \mathrm{Ni}$ and $\mathrm{Ti}_{5} \mathrm{Si}_{3}$ phases. The remaining three coatings have the same constitutional phases, which are $\mathrm{Ti}_{2} \mathrm{Ni} \mathrm{TiSi}_{2}$ and $\mathrm{Ti}_{5} \mathrm{Si}_{3}$. According to the data of Ref. [16], the values of Gibbs free energy $\left(\Delta \mathrm{G}^{0}\right)$ for the formation of $\mathrm{Ti}_{2} \mathrm{Ni}, \mathrm{TiSi}_{2}$ and $\mathrm{Ti}_{5} \mathrm{Si}_{3}$ phases were theoretically calculated (shown in Figure 4). Based on the data in Figure 4, all of the $\Delta G^{0}$ are negative, which demonstrated that all of the phases can be formed spontaneously during the laser cladding. It can be seen that the Ti-Si compounds have more negative standard free energy. Moreover, the reach between $\mathrm{Ti}$ and $\mathrm{Si}$ is more stable than that of $\mathrm{Ti}$ and $\mathrm{Ni}$. Ti and $\mathrm{Si}$ would tend to react with each other in the region rich in $\mathrm{Ti}$ and Si content. With the Si content increasing, the $\mathrm{TiSi}_{2}$ appeared.

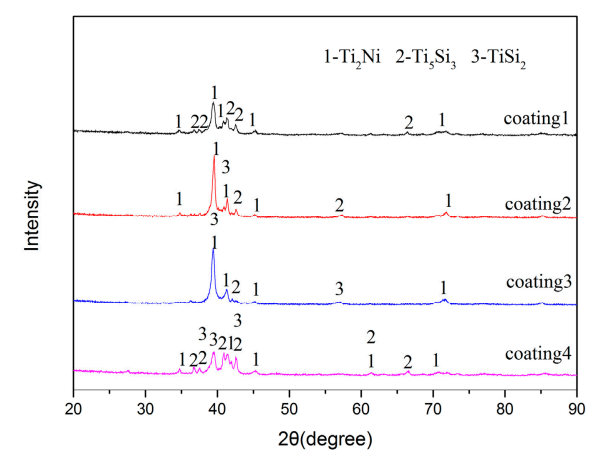

Figure 3. XRD patterns of the coatings.

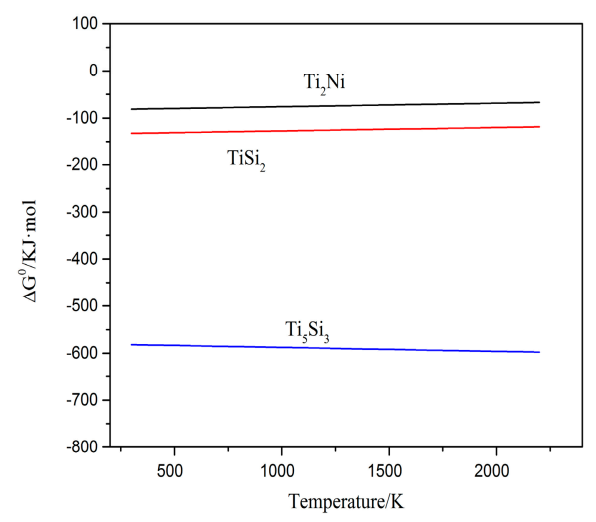

Figure 4. The Gibbs free energy $\left(\Delta \mathrm{G}^{0} / \mathrm{kJ} \cdot \mathrm{mol}\right)$ of the formation of Ni-Ti-Si compounds. 
Figure 5 indicates the macroscopic morphology in the cross section of coating. It can be found that the coating is metallurgically bonded well to the substrate and possesses dense microstructure without any microcracks and pores. The maximum thickness of the cross sectional profile of the coating is about $750 \mu \mathrm{m}$.

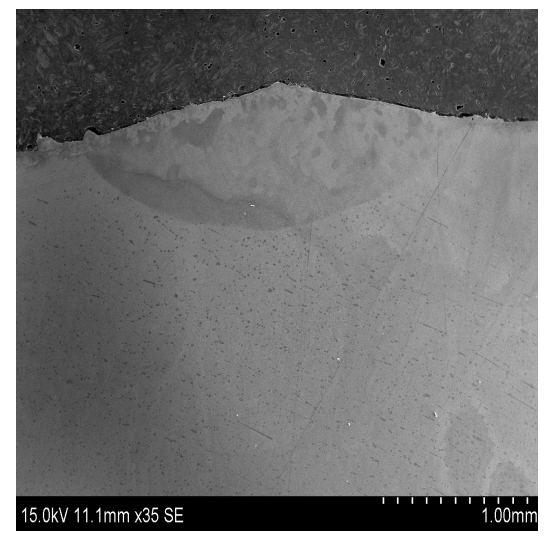

Figure 5. Macroscopic morphology in the cross section of coating.

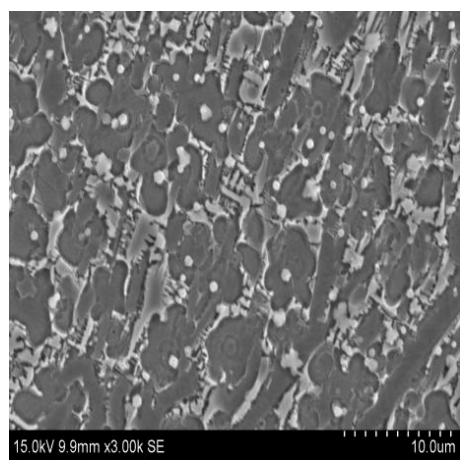

(a)

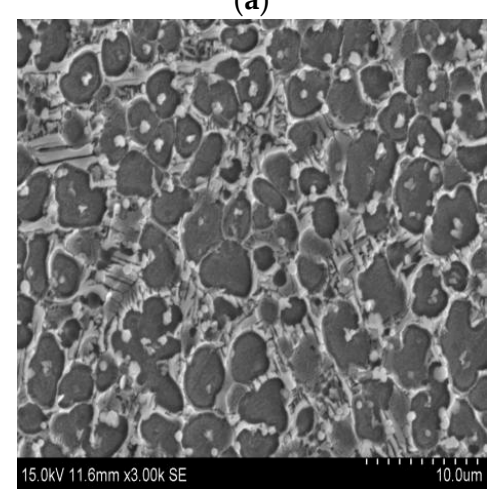

(c)

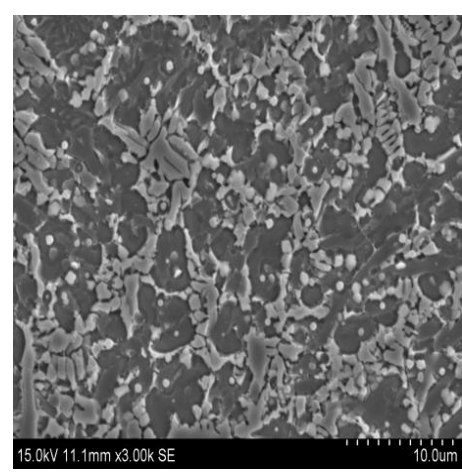

(b)

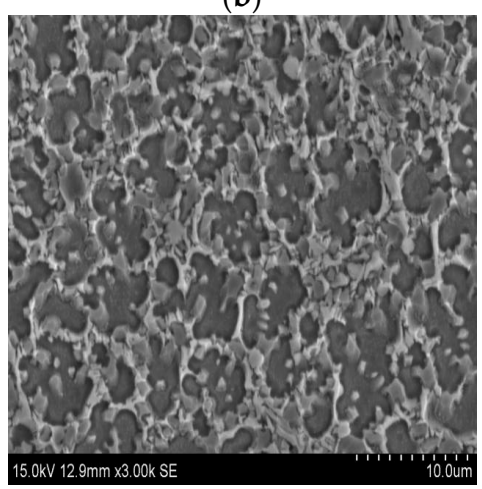

(d)

Figure 6. Microstructural characteristics of (a) coating 1 ; (b) coating 2; (c) coating 3; (d) coating 4 .

From Figure 6a, it can be seen that the coating is constituted of big black blocky phase, gray dendrites and a handful of white particles. With the decrease of Ti content, the number of the white particles is reduced, accompanied by the appearance of the greyish particles. To identify the chemical constitutions of these phases in coatings, EDS was used and the results are listed in Table 3. Because the laser cladding is a transient process, some elements in the substrate may be diluted into the coatings, such as Ti, Al and V. For coating 1 (Figure 7a), based on the data of phases 1 and 3, their atomic ratios of $\mathrm{Ti}$ and $\mathrm{Ni}$ are close to 2:1, respectively. Combined with the XRD patterns, 
the two phases can be identified as the $\mathrm{Ti}_{2} \mathrm{Ni}$ phase. Phase 2 is rich in $\mathrm{Ti}$ and $\mathrm{Si}$ whose atomic radios are approximately 5:3. Apart from the XRD results, phase 2 is supposed to $\mathrm{Ti}_{5} \mathrm{Si}_{3}$ reinforcement phase. The compositions of phases 4 and 6 are similar to that of phase 1 and 3, so phases 4 and 6 can be identified as $\mathrm{Ti}_{2} \mathrm{Ni}$ phase. Phase 5 is rich in $\mathrm{Ti}$ and $\mathrm{Si}$, which is the same as the constitution of phase 2. On the basis of the result in Figure 3, it can be proved as $\mathrm{Ti}_{5} \mathrm{Si}_{3}$ phase. For phase 7, the total content of $\mathrm{Ni}, \mathrm{Ti}, \mathrm{Al}$ and $\mathrm{V}$ is nearly $35.84 \%$, which is about half of the quantity of $\mathrm{Si}(64.16 \%)$. It reveals that phase 7 can be regarded as the $\mathrm{TiSi}_{2}$ phase.

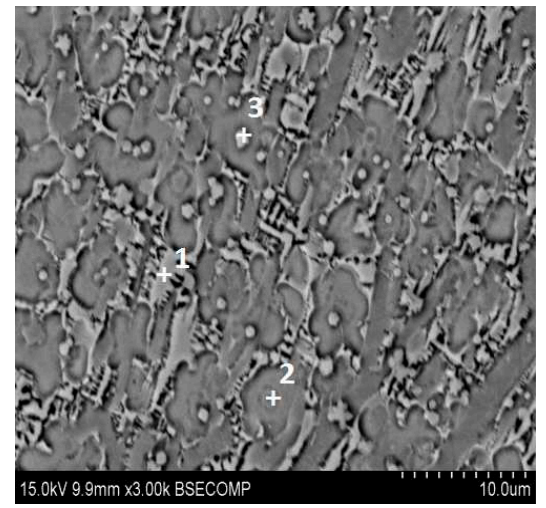

(a)

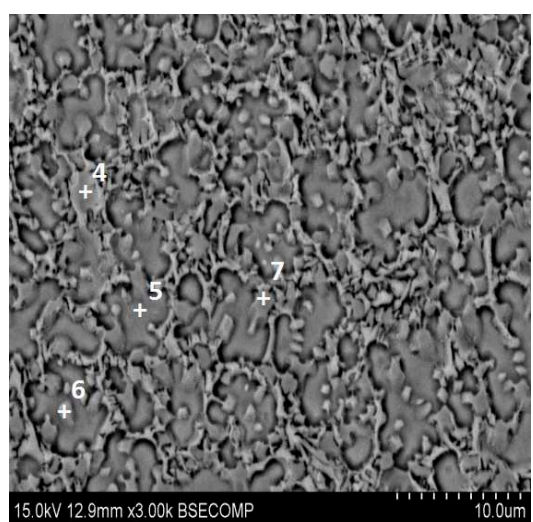

(b)

Figure 7. Microstructures of phases in coatings: (a) coating 1; (b) coating 4.

Table 3. EDS analysis results of the phases in coating 1 and coating 4 (at \%).

\begin{tabular}{cccccc}
\hline Phase & $\mathbf{N i}$ & $\mathbf{T i}$ & $\mathbf{S i}$ & $\mathbf{A l}$ & $\mathbf{V}$ \\
\hline 1 & 23.65 & 63.28 & 2.87 & 8.25 & 1.94 \\
2 & 3.37 & 65.04 & 34.77 & 6.39 & 3.37 \\
3 & 22.65 & 69.86 & 2.81 & 3.41 & 1.27 \\
4 & 27.45 & 62.06 & 3.11 & 5.93 & 1.46 \\
5 & 3.05 & 58.26 & 22.98 & 2.53 & 1.39 \\
6 & 28.05 & 57.73 & 3.25 & 8.92 & 2.04 \\
7 & 8.14 & 17.13 & 64.16 & 8.38 & 2.19 \\
\hline
\end{tabular}

During the rapid solidification process, the intermetallic compound $\mathrm{Ti}_{5} \mathrm{Si}_{3}$ preferentially precipitates from the molten pool as the primary phase due to its relatively higher melting point $(2403 \mathrm{~K})$ and more negative free negative of formation. Accompanying the solidification of the primary $\mathrm{Ti}_{5} \mathrm{Si}_{3}$ phase, the amount of $\mathrm{Ti}$ and $\mathrm{Si}$ in the residual liquid is insufficient for the formation of $\mathrm{Ti}_{5} \mathrm{Si}_{3}$ phase, and, therefore, $\mathrm{TiSi}_{2}$ phase is formed. Hence, the residual liquid is rich in $\mathrm{Ni}$. Finally, the $\mathrm{Ti}_{2} \mathrm{Ni}$ phase is formed by combining the Ti element, which may be from the substrate.

\subsection{Microhardness and Wear Resistance}

Figure 8 shows the microhardness distribution of the cladding coatings along the depth. It can be seen that the microhardness of the coatings is distinctly different with the different contents of Ti. It may be attributed to the microstructural variations and the constitutions. Judging from the Figure 8, the results can be drawn that a transition zero existed between the substrate and cladding coatings and the value of microhardness of the coating near the substrate declines remarkedly. This is mainly owing to the coating diluted by the substrate. In addition, the microhardness of the zero is higher than the substrate (approximately $370 \mathrm{HV}$ ) due to the formation of the reinforced phases in the zero. The average microhardness of the coatings is about $560 \mathrm{HV}, 826 \mathrm{HV}, 628 \mathrm{HV}$ and $765 \mathrm{HV}$, respectively. Compared with the coating 1, the microhardness of the remaining three coatings is all higher. This may be owing to the formation of the $\mathrm{TiSi}_{2}$ phase. $\mathrm{Ti}_{5} \mathrm{Si}_{3}$ and $\mathrm{TiSi}_{2}$ phases are both $\mathrm{Ti}$-Si 
intermetallic silicides, which have a significant impact on the microhardness of coatings due to their characteristic advantages of high hardness, high melting points, and well oxidation resistance [17].

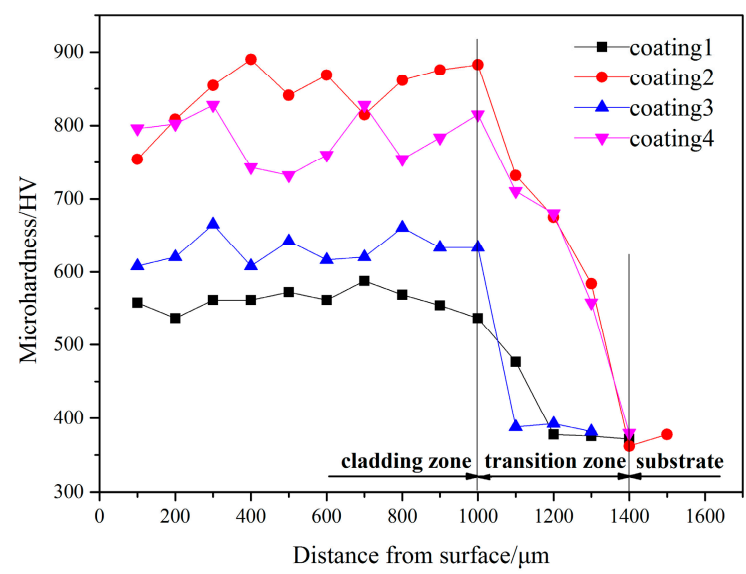

Figure 8. Microhardness of the laser cladding coatings along the depth.

The friction coefficients of the substrate and coatings against a WC (Tungsten Carbide) ball with the hardness of approximately $1600 \mathrm{HV}$ are shown in Figure 9. The average friction coefficient of the substrate is 0.416 and it is slightly lower than the friction coefficients of coatings, which are $0.545,0.546$, 0.488 and 0.448 , respectively. The friction coefficent of coating 4 fluctuates more smoothly than that of other coatings and substrate. It can be observed that with the decrease of the content of $\mathrm{Ti}$, the average friction coefficients of the coatings reduce, simultaneously. Figure 10 shows the surface profiles across the wear scars of the substrate and the cladding coatings. The wear track width and the depth of all coatings reveal that the wear resistance of all coatings are well improved, especially coating 4 .

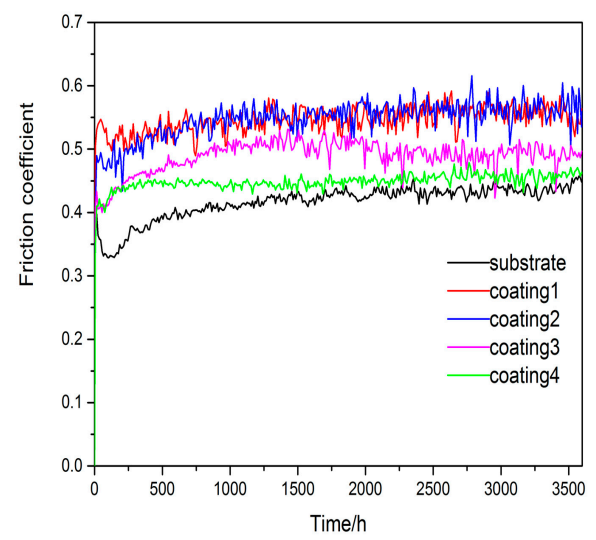

Figure 9. Friction coefficients of the substrate and laser cladding coatings at temperature.

To characterize the morphologies of the worn surfaces of the substrate and the coatings, SEM observation was carried out on the samples. As shown in Figure 11a, the substrate presents severe adhesive and abrasive wear due to the serious plastic deformation, deep plowing grooves and flaking debris. The substrate has low microhardness and hence the hard asperities of the WC counterbody are more likely to penetrate into the substrate, which results in the deep grooves. According to Figure 8, the cladding coatings all have comparatively higher microhardness than that of the substrate. Therefore, the wear mechanism of them is constituted of abrasive wear and the coatings exhibit a higher resistance to plastic deformation and scratching from the WC counterbody. The worn smooth surfaces of the coatings (Figure $11 \mathrm{~b}-\mathrm{e}$ ) sufficiently demonstrate it. The hard silicide phases $\left(\mathrm{Ti}_{5} \mathrm{Si}_{3}\right.$ and $\mathrm{TiSi}_{2}$ ) and relatively ductile phase $\left(\mathrm{Ti}_{2} \mathrm{Ni}\right)$ coexist in coatings. It is benefical for lessening the wear loss of materials. 
The $\mathrm{Ti}_{5} \mathrm{Si}_{3}$ phase plays an imperative role in abrasive and adhesive wear resistance due to its higher microhardness and large covalent-dominant atomic bonding. Furthermore, the $\mathrm{Ti}_{2} \mathrm{Ni}$ phase greatly combines the ductility and high microhardness, making a difference to support the hard silicide phase and defending the coating from brittle crack or fracture. Coatings exhibit outstanding wear resistance.

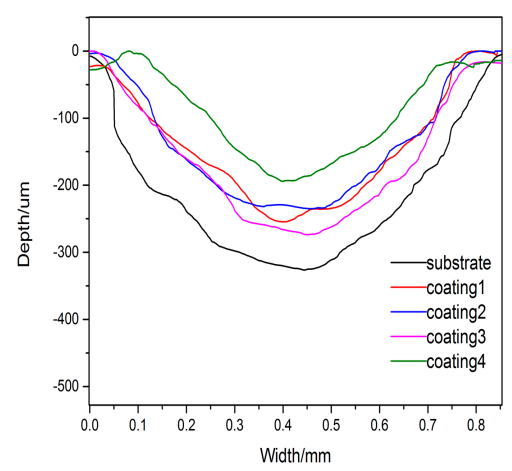

Figure 10. Profiles of the substrate and cladding coatings after friction and wear test.

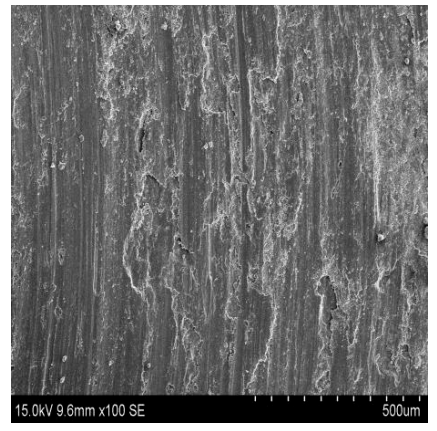

(a)

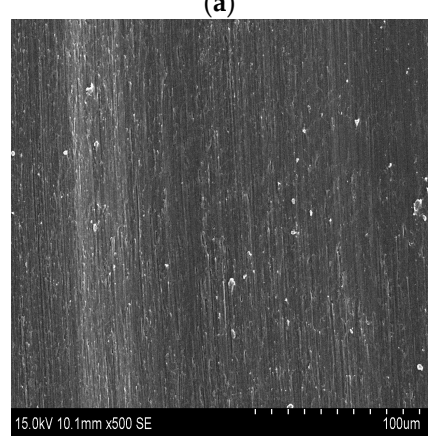

(c)

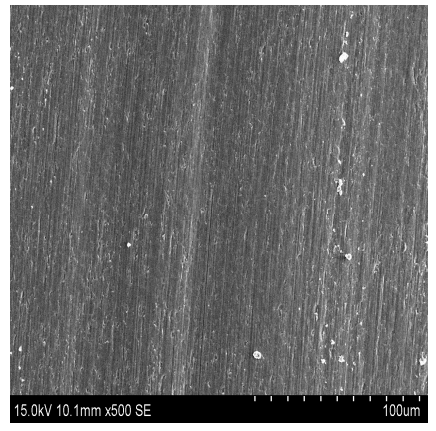

(b)

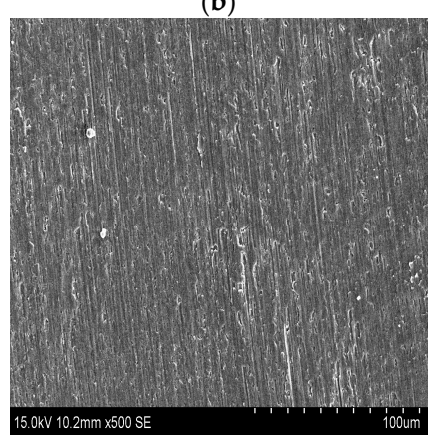

(d)

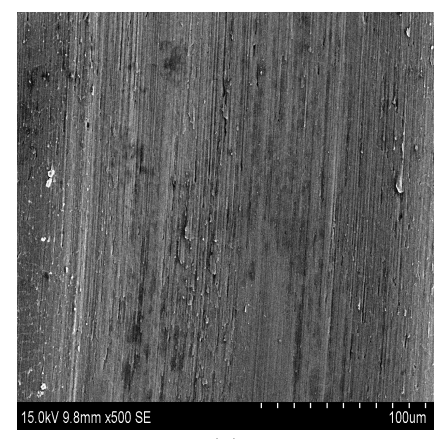

(e)

Figure 11. Worn surface morphologies of (a) the substrate; (b) coating 1; (c) coating 2; (d) coating 3; (e) coating 4 . 


\subsection{High Temperature Oxidation Resistance}

Figure 12 presents the oxidation weight gain curves of the substrate and cladding coatings exposed at $800{ }^{\circ} \mathrm{C}$ for $50 \mathrm{~h}$. Obviously, the weight of all the samples has a growing tendency with the elongation of oxidation time. In addition, the weight gain of coatings is clearly lower than that of the substrate at the same temperature during the oxidation. With the decrease of Ti content, the weight gain of coatings exhibits a regular change. For the coating with the Ti content between 30 at $\%$ and 50 at $\%$, the weight gain fluctuates insignificantly. When the Ti content of the coating is 20 at \%, the weight gain is decreased distinctly and about a half of the substrate. It can demonstrate that Ti content influences not only the phase constitutions of coatings but also the oxidation resistance.

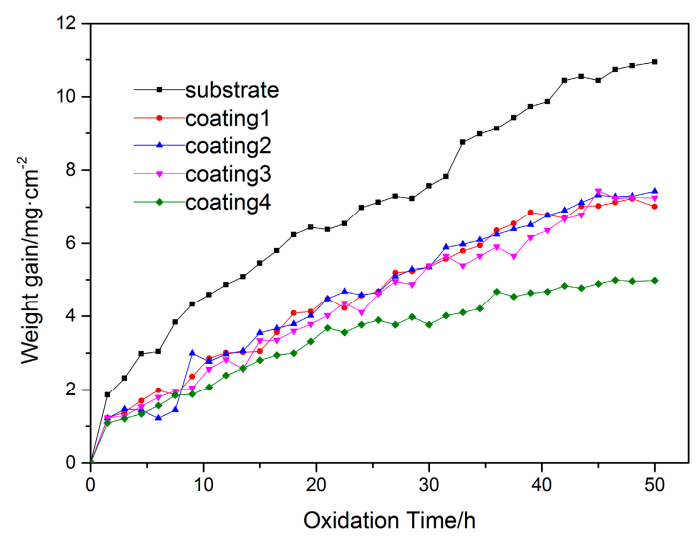

Figure 12. Oxidation weight gain curves of the substrate and cladding coatings at $800{ }^{\circ} \mathrm{C}$.

Based on the data acquired by high temperature oxidation (shown in Figure 12), the oxidation process for the substrate and coatings can be divided into two stages, which contains a sharp increase and relatively gentle growth in weight gain with the extension of time. During the initial stage, the speed of weight gain is quick because of the surface of samples is exposed in air without any protection. When the oxidation time is extended, the surface of the samples is surrounded by a layer of oxidation products that protect the samples are further oxidized. As a result, the fitted oxidation kinetics curves of them are different during different stages. In the first stage, the relationship between weight and oxidation time is fitted with a linear increase. The relative equation is listed as follows:

$$
y=a+b x
$$

where $y$ is the weight gain and $x$ represents the oxidation time. The values of $a$ and $b$ represent the intercept and the slope given in the table in Figure 13 . The value of $b$ is $0.379 \mathrm{mg} /\left(\mathrm{cm}^{2} \cdot \mathrm{h}\right)$, $0.349 \mathrm{mg} /\left(\mathrm{cm}^{2} \cdot \mathrm{h}\right), 0.345 \mathrm{mg} /\left(\mathrm{cm}^{2} \cdot \mathrm{h}\right), 0.311 \mathrm{mg} /\left(\mathrm{cm}^{2} \cdot \mathrm{h}\right), 0.289 \mathrm{mg} /\left(\mathrm{cm}^{2} \cdot \mathrm{h}\right)$, respectively. It reveals that the oxidation rate of the coatings is lower than that of the substrate. Therefore, the oxidation resistance of the coatings can be improved compared with the substrate. In the second stage, the growth of oxides formed in the oxidation test can be described by reaction rate equation [18], and the equation is expressed as follows:

$$
y=m x^{n}
$$

where $y$ is the weight gain, $x$ represents the oxidation time, $m$ is the oxidation rate constant and $n$ is the rate exponent. The value of $n$ obtained for all samples is $0.587,0.658,0.685,0.712$ and 0.53 , respectively, which is nearly close to 0.5 . Hence, the oxidation kinetics curve of the samples after the first stage is in accordance with a parabolic law. 


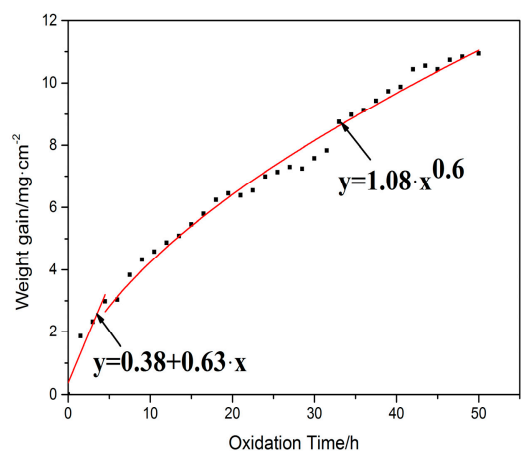

(a)

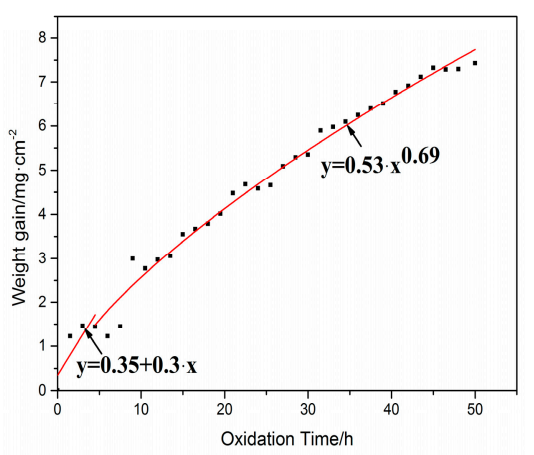

(c)

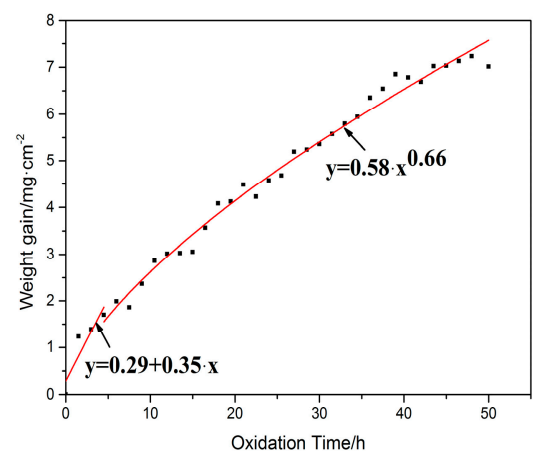

(b)

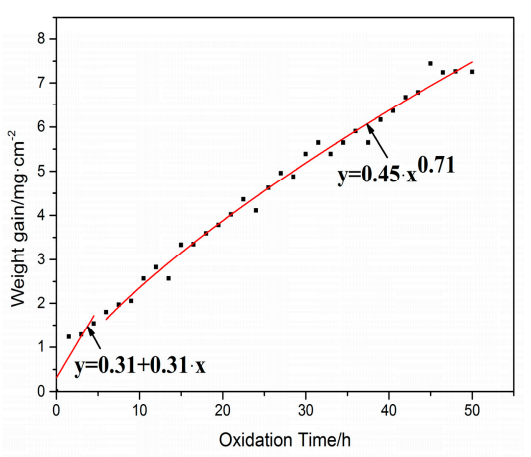

(d)

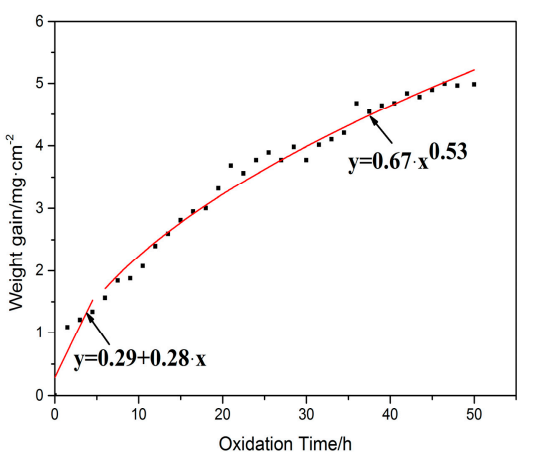

(e)

Figure 13. Oxidation weight gain fitted curves of the substrate and cladding coatings with different contents of Ti at $800{ }^{\circ} \mathrm{C}$ : (a) the substrate; (b) coating 1; (c) coating 2; (d) coating 3; (e) coating 4.

The SEM images and EDS analysis results of the substrate and coating 4 after high-temperature oxidation test for $50 \mathrm{~h}$ are shown in Figure 14 and Table 4 . The oxidized surface morphology of the substrate shown in Figure 14a,b, Figure 14c,d, and Figure 14e reveal the oxidized surface morphology of coating 4. Based on the element content listed in Table 4, it can be drawn that the chemical constitution of the oxidized surface of the substrate only embraces $\mathrm{Ti}, \mathrm{Al}$ and $\mathrm{O}$, namely the titanium oxide and aluminum oxide may be formed on the surface of the substrate during the oxidation process. Regions 8 and 9 all show relatively high content of Ti, which indicates that the amount of titanium oxide is larger. The residual elements in the substrate are not detected. The low content of the residual elements in the substrate may be attributed to the phenomenon. According to the data in Table 4, the $\mathrm{Ni}, \mathrm{Ti}, \mathrm{Si}, \mathrm{Al}$ and O elements are all detected in coating 4 after an oxidation test. That is to say, the oxides of coating 4 may contain four kinds. To identify the oxides in the samples, the XRD analysis is utilized. 


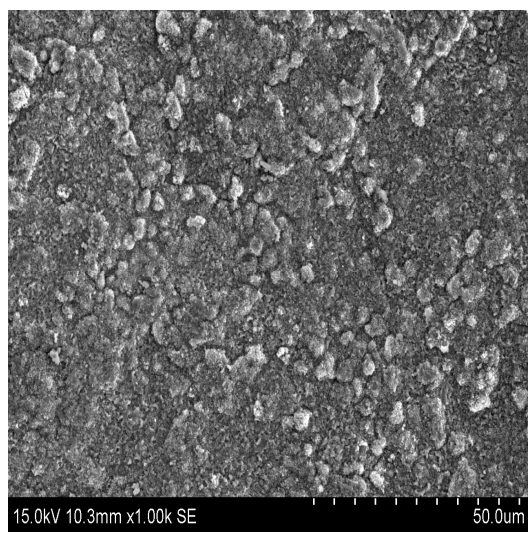

(a)

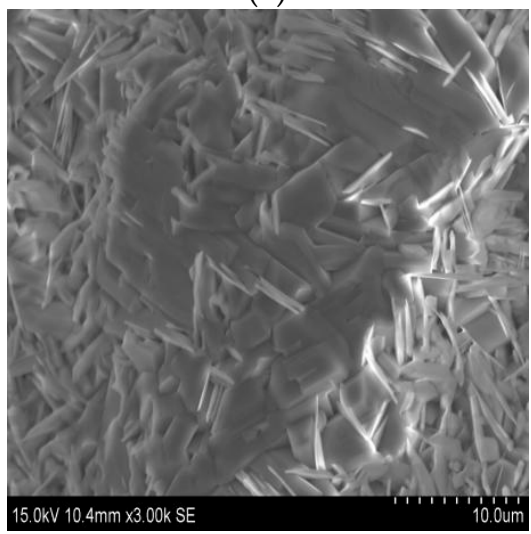

(c)

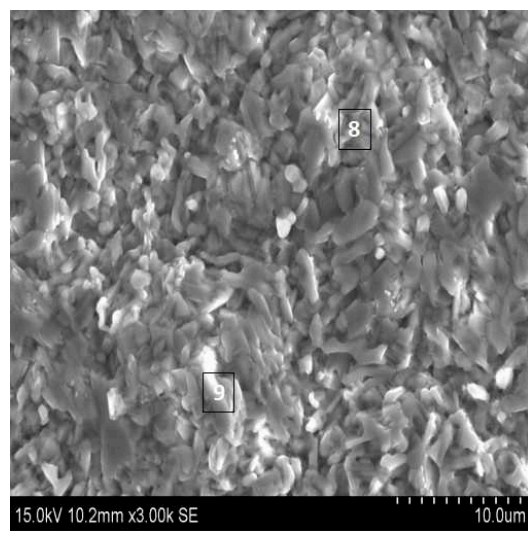

(b)

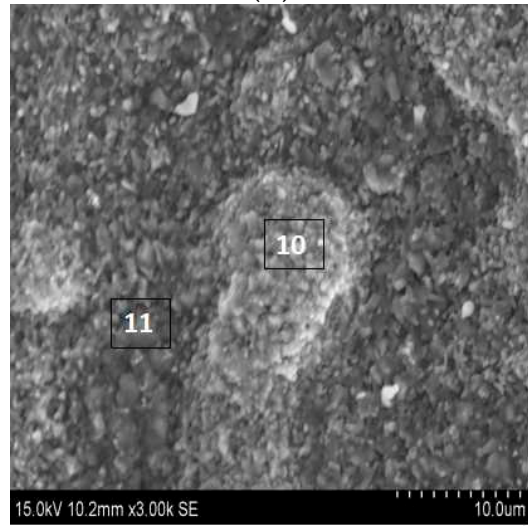

(d)

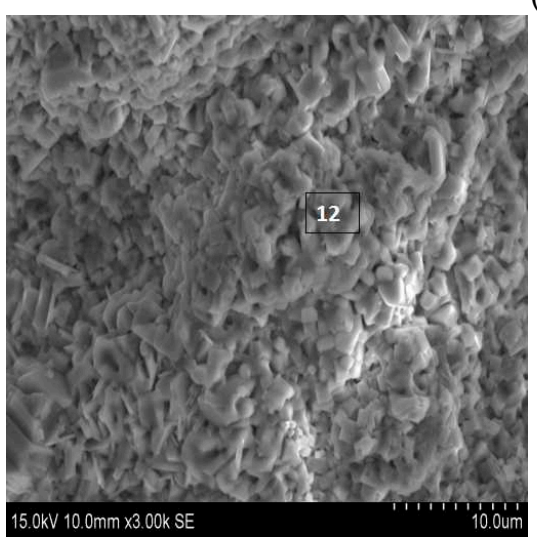

(e)

Figure 14. SEM morphologies of the substrate $(\mathbf{a}, \mathbf{b})$ and coating $4(\mathbf{c}-\mathbf{e})$ exposed at $800{ }^{\circ} \mathrm{C}$ for $50 \mathrm{~h}$.

Table 4. EDS analysis results of the regions in substrate and coating 4 after oxidation test (at \%).

\begin{tabular}{cccccc}
\hline Regions & Ni & Ti & Si & Al & O \\
\hline 8 & - & 34.59 & - & 0.83 & 64.58 \\
9 & - & 27.03 & - & 17.86 & 55.1 \\
10 & 1.55 & 25.12 & 0.92 & 22.89 & 49.48 \\
11 & 0.65 & 30.38 & 1.56 & 4.36 & 63.06 \\
12 & 0.86 & 18.85 & 8.22 & 4.01 & 68.06 \\
\hline
\end{tabular}

Figure 15 shows the XRD patterns of the oxidized films. Compared with oxides in the substrate that contain titanium oxides and aluminum oxide, the oxides of all coatings also involve the siilicon oxides. However, the oxides composed of other metal elements in material cannot be detected. It may 
be the low content of them that should be responsible for this phenomenon. Based on the data in Table 1, the chemical composition of the substrate is mainly composed of Ti and $\mathrm{Al}$ elements; hence, the oxides of the surface of the substrate are predominantly $\mathrm{TiO}_{2}$ and $\mathrm{Al}_{2} \mathrm{O}_{3}$. Because laser cladding is a rapid melting and rapid nonequilibrium solidification process, there is a small quantity of $\mathrm{Al}$ element diffused from the substrate to the coatings. Therefore, the oxide of coatings contains an $\mathrm{Al}_{2} \mathrm{O}_{3}$ phase. According to the XRD patterns, the phase constitutions of coatings exposed at $800{ }^{\circ} \mathrm{C}$ for $50 \mathrm{~h}$ are nearly the same. However, it is indisputable that there is no Ni oxide found despite the fact that the content of $\mathrm{Ni}$ in coatings is relatively high. It may be that the oxygen affinity between nickel and titanium is attributed to this phenomenon [19].

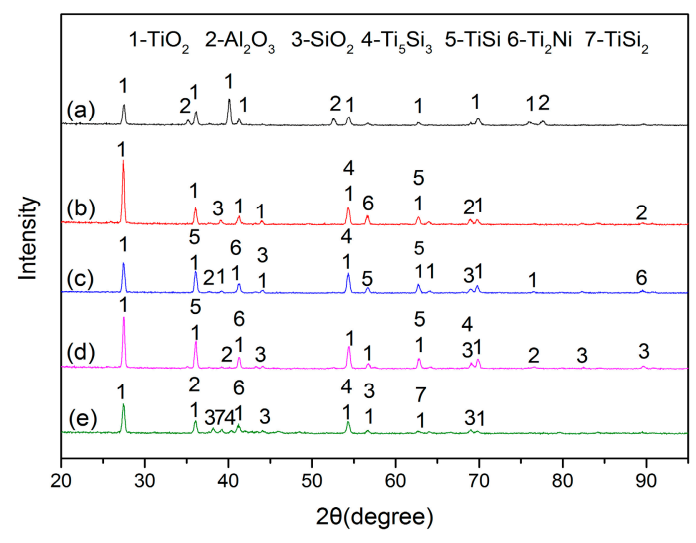

Figure 15. The XRD patterns of the specimens after oxidation test: (a) the substrate; (b) coating 1 ; (c) coating 2; (d) coating 3; (e) coating 4 .

Generally speaking, the Ti element is comparatively easier to be oxidized than the Ni element at the same temperature. It can also be demonstrated by the results in Figure 16. However, $\mathrm{Ti}_{2} \mathrm{Ni}$, $\mathrm{Ti}_{5} \mathrm{Si}_{3}$ and $\mathrm{TiSi}_{2}$ phases are simultaneously detected in coatings exposed at $800{ }^{\circ} \mathrm{C}$ for $50 \mathrm{~h}$. During the oxidation process, only partial phases are oxidized. It can explain that the weight gain of coatings is lower than that of substrate, especially coating 4 . The Ti-Si and Ti-Ni intermetallic compounds formed in coatings present better high-temperature oxidation resistance. In the coatings after oxidation tests, the TiSi phase is also detected. It may be ascribed to the reactions (3) and (4) [20]:

$$
\begin{gathered}
\mathrm{Ti}_{5} \mathrm{Si}_{3}+\mathrm{Si} \rightarrow \mathrm{TiSi} \\
\mathrm{Ti}_{5} \mathrm{Si}_{3}+\mathrm{O}_{2} \rightarrow \mathrm{TiO}_{2}+\mathrm{TiSi}
\end{gathered}
$$

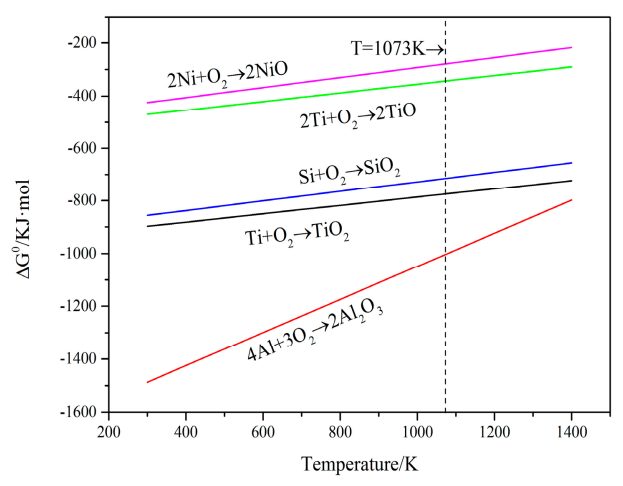

Figure 16. Variations of the standard free energy $\left(\Delta \mathrm{G}^{0} / \mathrm{kJ} \cdot \mathrm{mol}\right)$ of formation of some oxides with temperature. 
Figure 16 offers the relationship between the standard Gibbs free energy $\left(\Delta G^{0}\right)$ of formation of the conceivable oxides with temperature. The thermodynamic data came from Ref. [17]. Apparently, the standard Gibbs free energy of the formation of $\mathrm{Al}_{2} \mathrm{O}_{3}$ oxide is more negative than others during the oxidation temperature $(\mathrm{T}=1073 \mathrm{~K})$. Under the circumstances, those with adequate contents of $\mathrm{Ti}, \mathrm{Al}, \mathrm{Ni}$ and $\mathrm{Si}, \mathrm{Al}$ are apt to be preferentially oxidized at the test oxidation temperature [20]. Furthermore, the $\mathrm{Al}_{2} \mathrm{O}_{3}$ phase is more stable at the test temperature. The standard Gibbs free energy of formation of $\mathrm{NiO}$ is less negative than that of other oxides in the oxidation environment. It means that the $\mathrm{NiO}$ is relatively unstable and difficult to form. During the high temperature, Ti content may be oxidized to $\mathrm{TiO}$ and $\mathrm{TiO}_{2}$; however, only $\mathrm{TiO}_{2}$ is found in the XRD patterns. There are several reasons for this. Firstly, the standard Gibbs free energy of formation of $\mathrm{TiO}_{2}$ is more negative than that of $\mathrm{TiO}$. In addition, $\mathrm{TiO}$ contains anion vacancy. It stands for the stability of $\mathrm{TiO}_{2}$ being relatively high and easier to be formed, and, secondly, the affinity energy of $\mathrm{TiO}_{2}$ formed by $\mathrm{Ti}$ and $\mathrm{O}$ is $-54.99 \mathrm{eV}$, which is more negative than the affinity energy of $\mathrm{TiO}$ formed by $\mathrm{Ti}$ and $\mathrm{O}(-28.27 \mathrm{eV})$ [21]. With this reason, $\mathrm{TiO}_{2}$ in the practical oxidation process is generally detected compared with $\mathrm{TiO}$ while the monoxide is quickly oxidized to the dioxide [22]. It can be seen that the $\Delta \mathrm{G}^{0}$ of $\mathrm{TiO}_{2}$ is just slightly more negative than that of $\mathrm{SiO}_{2}$ and a little more stable. Therefore, the sequential order of the oxides for Ti and Si may be uncertain.

During the initial oxidation process of coatings, $\mathrm{O}$ atoms in the air contact the surface of coatings and a layer of oxides is formed with the extension of time. $\mathrm{TiO}_{2}$ is brittle and loose in the oxide film and it is easier to detach from the surface. Then, $\mathrm{O}$ atoms can diffuse from the channel and are oxided with elements inside. For coatings, there is a large amount of $\mathrm{Ti}_{5} \mathrm{Si}_{3}, \mathrm{TiSi}_{2}$ and $\mathrm{Ti}_{2} \mathrm{Ni}$ reinforcement phases. They can hinder the diffusion of $\mathrm{O}$ atoms and restrain the oxidation process. Coatings present excellent oxidation resistance. It can be proved by data from Figures 12 and 13. Moreover, coating 4 shows the best oxidation resistance.

\section{Conclusions}

Ti-Si and Ti-Ni intermetallic compounds composite coatings were fabricated by laser cladding using Ni-Ti-Si powders on Ti6Al4V substrate. The effect of the compounds on microstructure, microhardness and tribological properties were investigated. Moreover, the high-temperature oxidation resistance of the substrate and cladding coatings was also tested at $800{ }^{\circ} \mathrm{C}$ for $50 \mathrm{~h}$. The following conclusions can be drawn:

- Coatings constituted of $\mathrm{Ti}_{5} \mathrm{Si}_{3}, \mathrm{Ti}_{2} \mathrm{Ni}$ and $\mathrm{TiSi}_{2}$ phases were obtained by laser cladding with different contents of $\mathrm{Ni}, \mathrm{Ti}$ and $\mathrm{Si}$ powders. Because of the distribution of the inherent high hardness of these phases, the coatings have a higher microhardness than the substrate. While the proportion of the Ti content is 40 at \%, the coating has the highest microhardness, which is $826 \mathrm{HV}$.

- By means of combining the reinforcement phases of $\mathrm{Ti}_{5} \mathrm{Si}_{3}$ and $\mathrm{TiSi}_{2}$ with the relatively ductile phase of $\mathrm{Ti}_{2} \mathrm{Ni}$, the coatings present good wear resistance. Coating 4 shows the better wear resistance.

- The oxidation process can be divided into two stages, the rapid and the slow oxidation sections. The oxidation rate of the coatings is lower than that of the substrate during the process. With the decrease of Ti content, the oxidation rate gradually reduces. Moreover, coating 4 has the lowest oxidation weight gain rate. It can demonstrate that coating 4 presents the best oxidation resistance at high temperature.

- In the oxidation process, the oxides of coatings are mainly $\mathrm{TiO}_{2}, \mathrm{Al}_{2} \mathrm{O}_{3}$ and $\mathrm{SiO}_{2}$ compared with oxides of the substrate, which is only $\mathrm{TiO}_{2}, \mathrm{Al}_{2} \mathrm{O}_{3}$. Furthermore, the $\mathrm{Ti}_{5} \mathrm{Si}_{3}, \mathrm{Ti}_{2} \mathrm{Ni}$, TiSi and $\mathrm{TiSi}_{2}$ phases are also found in coatings. It can be ascribed to the good oxidation resistance of coatings. 
Acknowledgments: This research was continuously supported by the National Natural Science Foundation of China (51605276, 51375294 and 51405288), the Shanghai Automobile Industry Technology Development Fund (1604) and the Shanghai Science and Technology Committee Innovation Grant (17JC1400600 and 17JC1400601).

Author Contributions: Qiaoqiao Zhuang, Peilei Zhang and Hua Yan conceived and designed the experiments; Qiaoqiao Zhuang and Mingchuan Li performed the experiments; Peilei Zhang and Zhishui Yu contributed materials and tools; Qinghua Lu and Peilie Zhang provided advice in all issues; Qiaoqiao Zhuang wrote the paper. All of the authors were involed in writing the final paper.

Conflicts of Interest: The authors declare no conflict of interest.

\section{References}

1. Sheng, W.; Liu, D.; Wang, H.M. Microstructure and high-temperature wear behavior of laser clad Ni-Ti-Si ternary metal silicide coatings. Surf. Coat. Technol. 2008, 202, 2871-2877. [CrossRef]

2. Lv, Y.H.; Li, J.; Tao, Y.F.; Hu, L.F. Oxidation behaviors of the TiNi/ $\mathrm{Ti}_{2} \mathrm{Ni}$ matrix composite coatings with different contents of TaC addition fabricated on Ti6Al4V by laser cladding. J. Alloys Compd. 2016, 679, 202-212. [CrossRef]

3. Altus, E.; Konstantino, E. Optimum laser surface treatment of fatigue damaged Ti-6Al-4V alloy. Mater. Sci. Eng. A 2001, 302, 100-105. [CrossRef]

4. Dai, J.; Zhang, F.Y.; Wang, A.; Yu, H.J.; Chen, C. Microstructure and properties of Ti-Al coating and Ti-Al-Si system coatings on Ti-6Al-4V fabricated by laser surface alloying. Surf. Coat. Technol. 2017, 309, 805-813. [CrossRef]

5. Leyens, C.; Peters, M. Titanium and Titanium Alloys: Fundamentals and Applications; John Wiley and Sons, Ltd.: New York, NY, USA, 2003; ISBN 3-527-30534-3.

6. Zhang, P.L.; Liu, X.P.; Lu, Y.L.; Yan, H.; Yu, Z.; Li, C.; Lu, Q.H. Microstructure and wear behavior of Cu-Mo-Si coatings by laser cladding. Appl. Surf. Sci. 2014, 311, 709-714. [CrossRef]

7. Maliutina, I.N.; Si-Mohand, H.; Sijobert, J.; Bertrand, Ph.; Lazurenko, D.V.; Bataev, I.A. Structure and oxidation behavior of $\gamma$-TiAl coating produced by laser cladding on titanium alloy. Surf. Coat. Technol. 2017, 319, 136-144. [CrossRef]

8. Miranda, R. Laser Surface Modification of Alloys for Corrosion and Erosion Resistance; Woodhead Publishing Limited: Cambridge, UK, 2012; ISBN 978-0-85709-015-7.

9. Kathuria, Y.P. Some aspects of laser surface cladding in the turbine industry. Surf. Coat. Technol. 2000, 132, 262-269. [CrossRef]

10. Huang, C.; Zhang, Y.Z.; Vilar, R.; Shen, J.Y. Dry sliding wear behavior of laser clad TiVCrAlSi high entropy alloy coatings on Ti-6Al-4V substrate. Mater. Des. 2012, 41, 338-343. [CrossRef]

11. Weng, F.; Yu, H.J.; Chen, C.Z.; Dai, J.J. Microstructures and wear properties of laser cladding Co-based composite coatings on Ti-6Al-4V. Mater. Des. 2015, 80, 174-181. [CrossRef]

12. Dong, Y.J.; Wang, H.M. Microstructure and dry sliding wear resistance of laser clad TiC reinforced Ti-Ni-Si intermetallic composite coating. Surf. Coat. Technol. 2009, 204, 731-735. [CrossRef]

13. Liu, H.X.; Zhang, X.W.; Jiang, Y.H.; Zhou, R. Microstructure and high temperature oxidation resistance of in-situ synthesized $\mathrm{TiN} / \mathrm{Ti}_{3} \mathrm{Al}$ intermetallic composite coatings on $\mathrm{Ti} 6 \mathrm{Al} 4 \mathrm{~V}$ alloy by laser cladding process. J. Alloys Compd. 2016, 670, 268-274. [CrossRef]

14. Liu, X.B.; Wang, H.M. Microstructure wear and high-temperature oxidation resistance of laser clad $\mathrm{Ti}_{5} \mathrm{Si}_{3} / \gamma / \mathrm{TiSi}$ composite coatings on $\gamma$-TiAl intermetallic alloy. Surf. Coat. Technol. 2006, 200, 4462-4470. [CrossRef]

15. Lv, Y.H.; Li, J.; Tao, Y.F.; Hu, L.F. High-temperature wear and oxidation behaviors of $\mathrm{TiNi} / \mathrm{Ti}_{2} \mathrm{Ni}$ matrix composite coatings with TaC addition prepared on Ti6Al4V by laser cladding. Appl. Surf. Sci. 2017, 402, 478-494. [CrossRef]

16. Ye, D.L. Practical Inorganic Thermodynamics Manual, 2nd ed.; Metallurgy Industry Press: Beijing, China, 2002; ISBN 7-5024-3055-5.

17. Liu, J.; Bai, Y.N.; Chen, P.W.; Cui, N.F.; Yin, H. Reaction synthesis of $\mathrm{TiSi}_{2}$ and $\mathrm{Ti}_{5} \mathrm{Si}_{3}$ by ball-milling and shock loading and their photocatalytic activities. J. Alloys Compd. 2013, 555, 375-380. [CrossRef]

18. Callister, W.D.J.; Rethwisch, D.G. Fundamentals of Materials Science and Engineering: An Integrated Approach, 4th ed.; Wiley-VCH: Hoboken, NJ, USA, 2012; ISBN 978-1-118-06160-2. 
19. Zhang, L.; Xie, C.Y.; Wu, J.S. Oxidation behavior of sputter-deposited Ti-Ni thin films at elevated temperature. Mater. Charact. 2007, 58, 471-478. [CrossRef]

20. Chen, C.; Feng, X.M.; Shen, Y.F. Oxidation behavior of a high Si content Al-Si composite coating fabricates on Ti-6Al-4V substrate by mechanical alloying method. J. Alloys Compd. 2017, 701, 27-36. [CrossRef]

21. Dai, J.; Zhu, J.Y.; Chen, C.Z.; Weng, F. High temperature oxidation behavior and research status of modifications on improving high temperature oxidation resistance of titanium alloys and titanium aluminides: A review. J. Alloys Compd. 2016, 685, 784-798. [CrossRef]

22. Liu, G.L.; Li, Y. The electronic theory study on high-temperature oxidation mechanism of TiAl alloy. Acta Phys. Sin. 2012, 61, 1-5. [CrossRef]

(C) 2017 by the authors. Licensee MDPI, Basel, Switzerland. This article is an open access article distributed under the terms and conditions of the Creative Commons Attribution (CC BY) license (http://creativecommons.org/licenses/by/4.0/). 